\title{
Chronic Kidney Disease of Undetermined Etiology around the World
}

\author{
Matteo Floris ${ }^{\mathrm{a}}$ Nicola Lepori $^{\mathrm{a}}$ Andrea Angioi $^{\mathrm{a}}$ Gianfranca Cabiddu $^{\mathrm{a}}$ \\ Doloretta Piras $^{\text {a }}$ Valentina Loi $^{\mathrm{a}}$ Sundararaman Swaminathan ${ }^{\mathrm{b}}$ \\ Mitchell H. Rosner ${ }^{b}$ Antonello Pani ${ }^{a}$

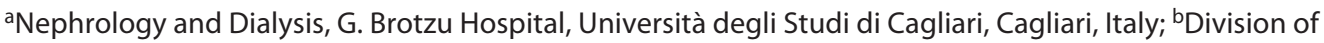 \\ Nephrology, University of Virginia Health System, Charlottesville, VA, USA
}

\section{Keywords}

Chronic kidney disease · Etiology · Mesoamerican

nephropathy · Chronic kidney disease of uncertain etiology

\begin{abstract}
Background: Epidemics of chronic kidney disease of uncertain etiology (CKDu) are occurring on the Pacific coast of Central America, in Sri Lankan and Indian agricultural communities, and in other hotspots around the world. CKDu primarily affects male agricultural workers, and traditional risk factors such as diabetes and hypertension are not involved in the pathogenesis. Although a causal factor has not yet been identified, culprits include repeated volume depletioninduced kidney injury, as well as exposure to agrichemicals, heavy metals and nephrotoxins contained in drugs, beverages, and traditional medications. Multiple risk factors may interact in a synergistic fashion thus resulting in chronic kidney damage. The absence of undefined protective factors may amplify the risk. Summary: This review focuses on the current understanding of CKDu by analyzing epidemiology, potential risk factors, and clinical and pathological features as well as geographical peculiarities of each disease. We also focus our attention on the etiology of these conditions in which multiple factors may synergistically contribute to the
\end{abstract}

development and progression of the disease. The last part of the manuscript is dedicated to the research agenda and practical recommendations. Key Messages: Since renal replacement therapy is not extensively available in areas where CKDu is widespread, prevention by avoiding all known potential risk factors is crucial. Innovative healthcare solutions and social policies in endemic areas along with collaborative clinical research projects are needed to better identify factors involved in disease promotion and progression.

(C) 2021 The Author(s)

Published by S. Karger AG, Basel

\section{Introduction}

Chronic kidney disease (CKD) represents a global public health problem with an etiology that varies across different populations [1]. While diabetes, hypertension, increased BMI, and smoking are well-known risk factors in the developed world [2], in developing countries, kidney disease is also caused by infectious glomerulonephritis and interstitial nephritis. Urolithiasis, long-term drug abuse, and environmental conditions also play a role [3].

(C) 2021 The Author(s)

Published by S. Karger AG, Basel

This article is licensed under the Creative Commons AttributionNonCommercial-NoDerivatives 4.0 International License (CC BYNC-ND) (http://www.karger.com/Services/OpenAccessLicense) Usage and distribution for commercial purposes as well as any distribution of modified material requires written permission.
Correspondence to:

Antonello Pani, antonellopani@aob.it 


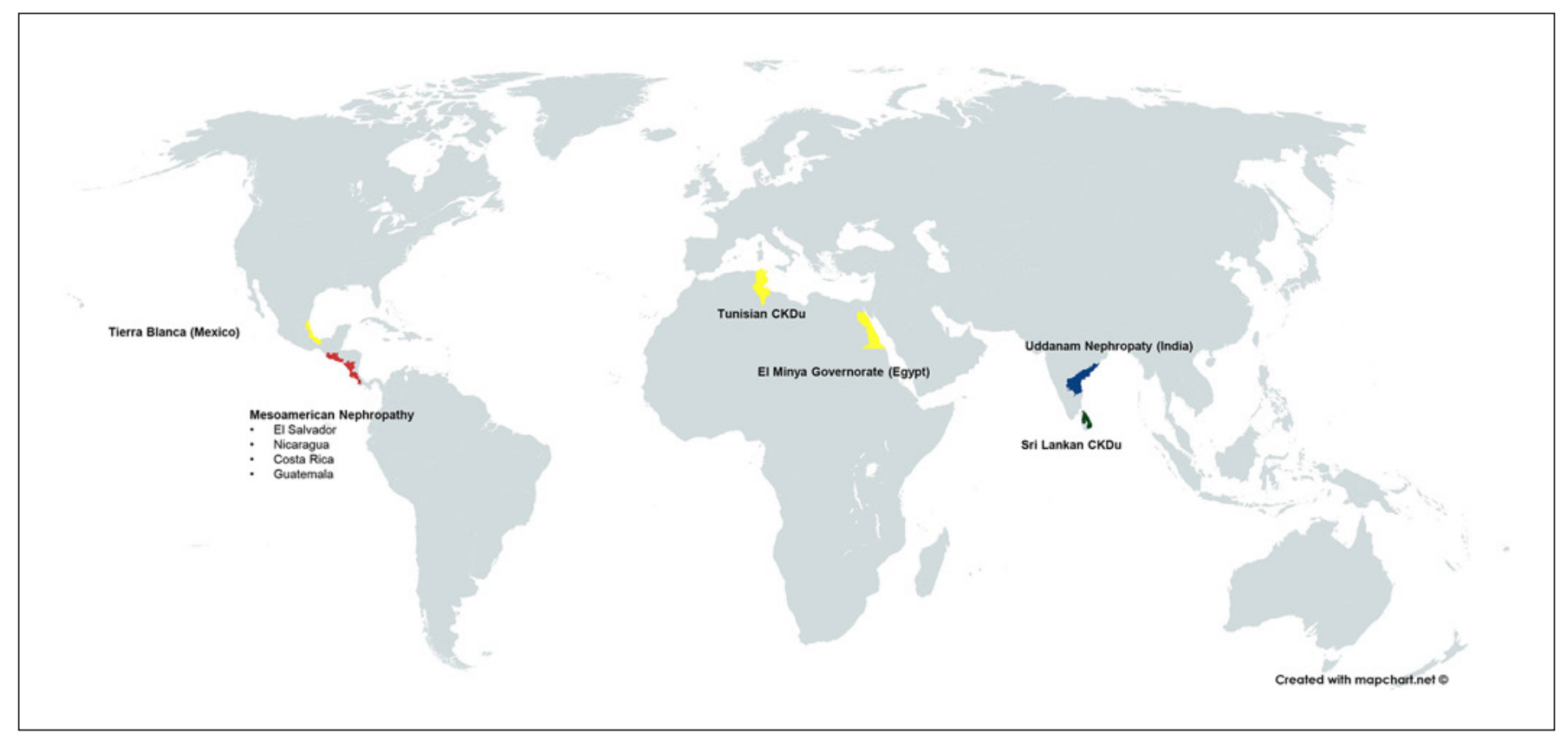

Fig. 1. CKDu areas around the world. MeN (red) in El Salvador [9], Nicaragua [13], Costa Rica [14], and Guatemala [15]. Sri Lankan CKDu (green) [34, 36]. Indian CKDu in the Uddanam region (blue) [54, 56]. Other CKDu hotspots (yellow): Tierra Blanca region (Mexico) [60], El Minya Governorate (Egypt) [63], and Tunisian CKDu [65]. CKDu, chronic kidney disease of uncertain etiology; MeN, Mesoamerican nephropathy.

Since the turn of the century, evidence has emerged of several epidemics of kidney disease of uncertain origin in many areas of the world. In some cases, the etiology has been established (i.e., cadmium exposure in Itai-itai disease [4] and Aristolochia species in Balkan endemic nephropathy [5]), while it remains unexplained in other parts of the world, being therefore termed chronic kidney disease of unknown (or uncertain) origin $(\mathrm{CKDu})$ or alternatively chronic interstitial nephritis in agricultural communities [6].

In 2006, SALTRA (Program on Work and Health in Central America) was the first program to recognize and promote an initiative against the abnormal prevalence of $\mathrm{CKD}$ in Central America. Although in use since early 2000, the use of the term CKDu expanded after its adoption by the International Society of Nephrology's International Consortium of Collaborators on Chronic Kidney Disease of Unknown Etiology in 2018. This entity was also already known by a number of different names ("CKD of nontraditional cause," "Mesoamerican nephropathy $[\mathrm{MeN}]$," "Balkan endemic nephropathy," "chronic interstitial nephritis in agricultural communities," "kidney disease of unknown cause in agricultural laborers," etc.) [7]. In some cases, the disease is identified by the name of the region or country of origin, as in rural communities on the Pacific coast of Central America $(\mathrm{MeN})$, the North-Central Province of Sri Lanka (Sri Lankan nephropathy), and the state of Andhra Pradesh of India (Uddanam nephropathy), and possibly in other countries like Egypt and Tunisia (Fig. 1).

In general, $\mathrm{CKDu}$ is a diagnosis of exclusion defined by (1) fulfilling the Kidney Disease Improving Global Outcomes (KDIGO) CKD criteria and (2) the absence of a recognized etiology or risk factor for CKD [7]. As a general rule, the disease is characterized by reduced estimated glomerular filtration rate (eGFR) and low levels of proteinuria. Moreover, when available, most renal biopsies show tubular atrophy and interstitial fibrosis with focal or global glomerulosclerosis. These findings are far from specific, and furthermore signs of active disease with acute tubular necrosis and interstitial nephritis are often reported. Lastly, unlike other forms of renal disease, a significant prevalence of $\mathrm{CKDu}$ is often observed in both small and large communities thereby impacting overall mortality and morbidity. Etiology is, by definition, unclear, but it would appear to be multifactorial. Renal function silently deteriorates to ESRD, which is often fatal in areas where only a few patients can afford renal replacement therapy [7], thereby representing a serious public health problem that needs to be addressed with renewed 
efforts in the coming years in Central America, Sri Lanka, and India [8-10].

In this review, we will discuss the epidemiology, potential causes and pathogenesis, and the clinical similarities between $\mathrm{CKDu}$ as reported from distinct locations worldwide. We will further discuss the additional contribution of genetics in CKDu pathogenesis and the current knowledge of preventive strategies.

\section{CKDu in Central America}

\section{Mesoamerican Nephropathy}

In Central America, an increase in CKD of unknown origin has been observed over the last 2 decades. The burden of disease appears to be higher among regions of the Pacific coast, while people living at higher altitudes show a significantly lower prevalence of CKD [11]. Of note, El Salvador has the highest mortality rate for CKD in the world, estimated at 51.8 deaths per 100,000 (in 2014, the USA had 1.1 deaths per 100,000). CKD is the fifth leading cause of death nationwide in people over 18 years of age and the second top cause of death overall in men [9]. However, there is no comprehensive or country-specific estimation of CKDu mortality. Of note, occupation and working conditions seem to be risk factors: $>40 \%$ of sugarcane and cotton plantation workers show an increase in serum creatinine $(\mathrm{sCr})>1.5 \mathrm{mg} / \mathrm{dL}$ after 10 years of work [11]. Port workers, miners, and construction workers also have an increased risk [8]. The disease appears to affect predominantly 20 - to 60 -year-old men [12], with an M:F ratio that ranges from 2:1 to 5:1 [11]. In El Salvador farming communities, the prevalence of CKD among adults is $15-21 \%$, less than half of who have traditional risk factors like diabetes or hypertension. From this it is inferred that a substantial proportion of the remaining half are affected by CKDu, although renal biopsy data are extremely limited in this cohort.

The burden of CKDu in Nicaragua can be gleaned from the few available reports. In a 2010 cross-sectional study, CKD prevalence was found to be higher among people living at sea level compared to those living at high altitudes, suggesting a role for heat stress and chronic dehydration. In fact, prevalence was considerably higher among workers at banana and sugar cane plantations [13]. In the Guanacaste province of Costa Rica, the number of new ESRD cases reached epidemic proportions, all of which involved young men working as sugar cane cutters [14]. In 2012, the highest prevalence of CKD/ESRD in Guatemala was in Guatemala City, fol- lowed by the departments of the Southwest Pacific coast. As compared to 2007, in 2010, CKD-associated mortality rose from 6 to 9.6/100,000 [15]. The etiology of ESRD has not been identified, but many cases are thought to be secondary to $\mathrm{MeN}$ as the geographic distribution (higher in the high temperature and sugar cane-growing regions) resembles the situation in Nicaragua and El Salvador.

\section{Clinical and Histological Features}

In the majority of cases, the clinical course of $\mathrm{MeN}$ is characterized by a progressive reduction in GFR in otherwise asymptomatic individuals [15]. Clinical presentation is nonspecific. As a general rule, patients progressively complain of muscle weakness, likely associated with hypokalemia and dysuria, which is often self-treated with a mixture of anti-inflammatory drugs, diuretics, and antibiotics [16]. Low-grade proteinuria has been inconsistently reported and usually appears during the later stages of CKD, while nephrotic range proteinuria is uncommon [10-17]. Hyperuricemia and hypokalemia are frequently described, and markers of tubulointerstitial injury such as neutrophil gelatinase-associated lipocalin and $\mathrm{N}$-acetyl-beta-D-glucosaminidase are significantly increased during the cane cutting season [18]. Significant urinary loss of electrolytes, including magnesium, phosphorus, sodium, potassium, and chloride [19], is also present.

Kidney ultrasound exam, often performed in the late stages, invariably shows small echogenic kidneys with no specific structural patterns [15]. Consistent with the clinical features, pathological examination reveals primary tubulointerstitial involvement. Recently, however, Wijkström and colleagues [17] reported that in addition to mild-moderate tubular atrophy and interstitial fibrosis, different degrees of global glomerulosclerosis $(7-70 \%$ of analyzed glomeruli), glomerular hypertrophy, and mild intimal hyperplasia were also observed. Electron microscopy examination revealed podocyte foot-process effacement and mild thickening of the glomerular basement membrane. The extent and causes of glomerular pathology in $\mathrm{MeN}$ are poorly understood; however, it may be primarily a secondary effect of tubulointerstitial disease. As is the case in patients with extensive tubulointerstitial pathology of any cause, remaining functional nephrons develop glomerulomegaly in response to glomerular hypertension and via other adaptive mechanisms. This process would contribute to proteinuria and accelerated loss of GFR [20]. 


\section{Potential Causes}

The cause of endemic CKD in Central America is currently unknown. The geographical distribution of the disease suggests that environmental heat stress might be a critical factor for the development of MeN. Low-altitude areas along the Pacific coast are characterized by extreme heat and humidity, with air temperatures often exceeding $38^{\circ} \mathrm{C}$. Sugarcane cutters are subject to prolonged and recurrent exertion often with insufficient fluid intake to replace the losses [21]. Recurrent volume depletion might predispose to CKD as a consequence of pathological processes that persist after maladaptive repair of acute kidney injury (AKI). This consists of a vicious cycle of endothelial injury, glomerular hyperfiltration, and interstitial fibrosis that leads to progressive organ damage [22]. Roncal Jimenez and colleagues [23] demonstrated that in a mouse model of recurrent volume depletion caused by repeated heat stress, water deprivation can induce proximal tubular injury, early renal fibrosis, and an increase in $\mathrm{sCr}$ through hyperactivation of the polyol-fructokinase pathway. The acute and recurrent rise in plasma osmolality leads to increases in sorbitol and fructose that is metabolized by fructokinase in the proximal tubule thus resulting in ATP depletion, oxidant tubular damage, and fibrosis [24]. The consequences of the hyperactivation of this pathway might theoretically be worsened by an excessive consumption of fructose-enriched beverages [15]. Furthermore, the rise in serum uric acid concentration as a consequence of physical activity under scorching conditions may lead to glomerular injury altering kidney autoregulation and, when associated with an increase in urine osmolality, to uric acid precipitation $[25,26]$. Suboptimal fluid intake has been linked with numerous diseases, including renal failure in general population, through the upregulation of serum- and glucocorticoid-inducible kinase 1 [27]. Nevertheless, there are some concerns regarding the hypothesis that dehydration is the primary cause of the epidemic. Firstly, there is currently no evidence that potential and recurrent prerenal injury may lead to CKD in the absence of comorbidities in a relatively young population such as Mesoamerican agricultural workers. In addition, comparable diseases are not seen in workers in more tropical areas, whereas in CKDu hotspots, even people who are not directly involved in manual labor or exposed to hot conditions develop the disease [28].

Although there is concern that exposure to pesticides and heavy metals might contribute to endemic CKDu in Central America [29], recently published studies have been unable to link any specific agrichemical directly to CKD [30]. In addition, an abnormal increase in $\mathrm{sCr}$ has been re-

Chronic Kidney Disease of Undetermined Etiology ported in other job categories with no direct occupational exposure to agrichemicals [18]. A recent survey among 100 workers in Western Nicaragua failed to detect any substances in concentrations above the United States Environmental Protection Agency (USEPA) limits. Further, no differences in arsenic exposure were reported among job categories, but the highest urinary excretion of arsenic was positively associated with a significant increase in $\mathrm{sCr}$ and GFR reduction [18]. In Nicaragua, the consumption of lija, a sugarcane-derived alcohol that may easily be contaminated during the distillation process, has been proposed as a potential risk factor for $\mathrm{MeN}$ [30], and lead contamination of spirits from unregulated informal distillers has been reported [31]; presently, no specific nephrotoxin has been identified, and, further, MeN has been described even in areas where lija consumption is uncommon. Taken together, these findings make it appear unlikely that a single pesticide or heavy metal contaminant is responsible for $\mathrm{CKDu}$. However, further study is required before this can be confirmed. It remains possible that nephrotoxic industrial contaminants interact with other factors to contribute to disease development or progression.

Among other potential risk factors, the consumption of nephrotoxic drugs like NSAIDs and antibiotics such as aminoglycosides has been studied. Although NSAIDs are commonly used in Central America with a prevalence that varies between 20 and $70 \%$, daily use is not frequent and is not positively associated with decreased renal function [32]. Limited available data do not show a correlation with the increase in CKD, but further studies are required. Endemic infections such as leptospirosis, which is more common among agricultural workers, have been proposed as a possible cause [33]. Renal manifestations of leptospirosis vary from subclinical infection to AKI [34]. While infections may cause a single episode of AKI, there is no current evidence suggesting a risk of increased progression to CKD. Finally, contaminated food or herbal remedies containing aristolochic acid are considered the likely cause of endemic tubulointerstitial nephritis, hypertension, and urothelial cancer in the Balkan region [35]. Nevertheless, the clinical features (including the lack of increased incidence of urothelial neoplasms), predilection of male gender, and the widespread distribution of the disease make it unlikely that aristolochic acid is the primary cause of MeN. Whatever the cause or causes of $\mathrm{MeN}$, it is likely that their impact is worsened by the burden of poverty in affected populations, which is associated with malnutrition and increased exposure to toxins that can cause AKI, such as copper sulfate, ethylene glycol, and paraquat [9], amongst others. 


\section{Sri Lankan CKDu}

\section{Epidemiology}

In 1994, an epidemic of CKD of unknown origin was described in dry agricultural areas of the North-Central Province (NCP) of Sri Lanka [36]. Now, 25 years after the first report, $\mathrm{CKDu}$ is recognized as the most significant public health issue in the NCP, affecting $>60,000$ individuals, with almost 20,000 deaths every year. The affected area currently covers almost one-third of the country [9], and CKDu has recently been reported as the seventh leading cause of death nationally [37].

In 2011, Athuraliya et al. [38] showed that in the community of Medawachchiya, a dry region located in the north, $87 \%$ of CKD cases did not have a clear cause or risk factor. Men who had resided in low-altitude farming communities for at least 5 years usually had more severe disease [39]; a higher risk for CKDu in farmers has also been described [39]. Interestingly, data from the central and southern parts of the island showed that CKDu patients made up between 2.9 and $9.1 \%$ of the CKD burden. However, since local agricultural techniques are different from those that are used in the NCP, a role for occupational factors has been suggested. This entity resembles Balkan nephropathy (mild proteinuria without active sediment, absence of diabetes or longstanding hypertension, and tubulointerstitial disease); thus, a possible role for herbal preparations is being studied, but has not yet been established. On the other hand, exposure to chronic dehydration and pollutants may expose farmers to slowly developing tubulointerstitial nephritis [40].

\section{Clinical and Histological Features}

Historically, onset occurs in the fifth decade and is characterized by hypertension, progressing to edema and ESRD [41, 42]. Since the disease has gained wider recognition, community screening programs have been promoted allowing early diagnosis [43]. In the initial stages, $\mathrm{CKDu}$ is largely asymptomatic, although patients describe recurrent dysuria with back pain and sterile urine; low proteinuria and mildly reduced GFR are usually observed. Although CKDu is clinically indistinguishable from other forms of CKD, several markers have been proposed as diagnostic tools for CKDu. Recently, a panel of 3 urinary biomarkers (kidney injury molecule, osteopontin, and retinol binding protein 4) showed good sensitivity and specificity $(>0.93)$ for distinguishing between $\mathrm{CKDu}$ and other causes of CKD [44], thus representing a set of potentially sensitive diagnostic tools. Unfortunate- ly, the cost of performing these tests precludes widespread use in a national screening program.

An essential tool for diagnosis is renal biopsy. Tubulointerstitial damage is universally reported, though rarely showing a severe degree of fibrosis, and is usually associated with lymphocytic infiltrate, thereby supporting a role for interstitial inflammation in disease progression. Different degrees of glomerular damage have been reported including global sclerosis (15-45\%), ischemictype obsolescence with wrinkled and collapsed glomerular tufts (18-64\%), and glomerular enlargement (3645\%) [45]. An interesting study which focused on histological features observed by electron microscopy showed large dysmorphic lysosomes with a light-medium electron-dense matrix containing dispersed dark electron-dense nonmembrane-bound aggregates [46]. Similar features have been described in calcineurin inhibitor nephrotoxicity, suggesting a toxic etiology, potentially mediated by the calcineurin-inhibiting effect of herbicides and insecticides.

\section{Risk Factors and Etiological Hypothesis}

Studies exploring the etiology of CKDu have focused on several potential causative agents. Although a fourfold-higher risk has been reported in individuals working for $>6 \mathrm{~h}$ in these conditions and in individuals drinking $<3 \mathrm{~L}$ of water per day [47], CKDu is not observed in the northern tip of Sri Lanka despite harsher environmental conditions than in NCP, thus supporting the hypothesis that factors other than climate could be involved in the pathogenesis.

A higher prevalence of $\mathrm{CKDu}$ is seen in communities whose sources of drinking water are shallow wells close to irrigation systems, with demonstrable seepage from the irrigation system to the wells. Moreover, drinking water from wells sourced by natural springs appears to be a protective factor [48].

A relationship between pesticide exposure and CKDu risk has been suggested. Jayasumana et al. [49] reported a strong increase in CKDu risk related to drinking well water, a history of drinking from recently abandoned wells, and the use of glyphosate. Theoretically, the hard water in endemic areas can convert glyphosate to solid complexes of metal (particularly magnesium, calcium, cadmium, and strontium) and arsenic (GMA complexes) which once adsorbed in the small intestine by the divalent metal transporter-1 are poorly metabolized in the liver. The renal environment, and especially the glomerularproximal tubule area, may provide a particular microenvironment that is able to breakdown GMA complexes 
thus leading to glomerular and tubular damage caused by both heavy metals and arsenic [50].

Although chronic heavy metal exposure has been associated with repeated AKI episodes thus potentially leading to CKD [51], data regarding the involvement in $\mathrm{CKDu}$ pathogenesis in Sri Lanka are conflicting. High levels of cadmium in water reservoirs serving endemic $\mathrm{CKDu}$ areas have been reported but not confirmed in subsequent studies $[52,53]$. Results on cadmium urinary excretion are also inconsistent. Some authors showed reduced urinary excretion (suggesting low renal expression of metallothionein, leading to tubular damage), while other evidence demonstrated elevated cadmium urinary excretion [54, 55]. Urine arsenic levels above the threshold limit for arsenic-related nephropathy have been demonstrated in $68 \%$ of CKDu patients and in $28 \%$ of controls thus suggesting a potential link between chronic arsenic toxicity and $\mathrm{CKDu}$ [56]. Moreover, as described in $\mathrm{MeN}$, leptospirosis is endemic in Sri Lanka and has been linked to $\mathrm{CKDu}$ [57].

\section{Indian CKDu (Uddanam Nephropathy)}

An elevated prevalence of CKD of unknown origin in the Uddanam region (coastal regions of the Indian state of Andhra Pradesh) was initially reported in the early 1990s [58]. In 2010, data from the first Indian CKD registry reported $\mathrm{CKDu}$ as the second most common cause of CKD, accounting for $16 \%$ of CKD cases [59]. Data from the Uddanam region reported a prevalence of CKD ranging between 40 and $60 \%$ (compared to the national prevalence of $17.2 \%$ ) with $40 \%$ of CKD cases classified as $\mathrm{CKDu}$ [60]. Similar to other types of CKDu, Uddanam nephropathy mainly affects men between 30 and 60 years of age, with a higher prevalence among farmers. The histological features include tubulointerstitial fibrosis, tubular atrophy, and a variable degree of lymphocytic peritubulitis, with no evidence of severe vascular or glomerular damage [61].

Several etiologic hypotheses have been proposed for Uddanam nephropathy, although robust data in this field are still lacking. The relatively low prevalence of CKDu in other rural Indian regions which have the same climate as Uddanam does not support the "heat stress hypothesis" [62]. Elevated blood concentrations of total hexachlorohexane, alfa-hexachlorohexane, gamma-hexachlorohexane, alfa-endosulfan, beta-endosulfan, aldrin, dichlorodiphenyldichloroethylene, and total pesticides have been reported in CKDu patients [63].

Chronic Kidney Disease of Undetermined Etiology

\section{Other CKDu Hotspots}

There are reports of high rates of CKD in other regions of the world with tropical climates. Tierra Blanca, in the Mexican State of Veracruz, is a rural region located in the eastern portion of the country, close to the Gulf of Mexico, with an agriculture-based economy [64]. Reported CKD prevalence among the inhabitants of Tierra Blanca is $25 \%, 44 \%$ of whom had no identifiable cause and thus could be considered CKDu cases [65]. Preliminary reports focused on exposure to nephrotoxins and heavy metals via water pollution [66], yet results from a government-commissioned investigation were unable to demonstrate an increased concentration of metals or other chemical toxins in irrigation and consumed water [64].

An increasing prevalence of ESRD was reported in El Minya Governorate of Egypt between 2002 and 2007, showing a $27 \%$ prevalence of CKD of unknown origin [67]. Risk factors associated for CKDu were drinking from tube wells, family history of renal disease, living in a rural area, and pesticide exposure [68].

In 2003, Hassen et al. [69] described chronic interstitial nephritis showing clinical and histological features strikingly similar to CKDu in the Tunisian population. The disease progress is slow and insidious and is now a leading cause of ESRD in the fourth and fifth decades of life [69]. High levels of ochratoxin A, a natural mycotoxin with nephrotoxic properties, were found in the food consumed by, and in human serum collected from, CKDu patients. Despite this, not all individuals who are heavily exposed to these risk factors develop CKD, suggesting a genetic predisposition [70].

\section{Is There a Role for Genetics in Solving the Puzzle of CKDu?}

Evidence supporting a role for genetics in $\mathrm{CKDu}$ is conflicting. Although no specific high-risk genetic pattern has yet been identified in the $\mathrm{MeN}$-affected population, several authors have described genetic risk factors for other forms of CKDu. A whole-exome sequencing study showed a correlation between Sri Lankan CKDu and a rare variant in the KCNA10 gene which encodes for a voltage-gated potassium channel found in proximal tubular cells [71]. An association with polymorphisms in the CYP1A1 gene and in genes codifying for xenobiotic metabolizing enzymes has been reported in patients with Uddanam nephropathy, suggesting a possible interplay between environmental toxins and genetic predisposition $[72,73]$. As the most common histological finding in $\mathrm{CKDu}$ is tubulointerstitial nephritis, it has been hypoth-

Kidney Blood Press Res 2021;46:142-151 147 
esized that some cases may be due to autosomal dominant tubulointerstitial kidney disease (ADTKD). ADTKD is a poorly understood and frequently misdiagnosed disorder [74] with a prevalence of approx. 1.7-1.8 per million [75] that may in fact be $>5$ times higher [76]. However, presently there are no reports regarding ADTKD prevalence in endemic CKDu regions.

The potential role of genetic testing for identifying the cause of nephropathy of unknown cause was recently demonstrated by Gharavi et al. [77], who performed exome sequencing in 3,315 patients with CKD selected from 2 independent cohorts. The first cohort $(1,128$ individuals) involved patients recruited from 280 centers in 25 countries, while the second cohort (2,187 individuals) was made up of patients seen at the Columbia University Medical Center. Interestingly, $8.5 \%$ of these patients had nephropathy of unknown origin, and a genetic defect was found in a high percentage of patients in this group (48 of $281,17.1 \%)$, with a broad range of mutations, encompassing defects of collagen (either COL4A3, COL4A4, or COL4A5), UMOD-associated tubulointerstitial disease, mutations in PKD1, and other less frequent defects. Nephropathy of unknown origin was shown to be an independent predictor of having a genetic diagnosis [77]. Moreover, CKD is more often a polygenic trait. In patients with CKDu, but without a known genetic diagnosis, genetics might still be useful through the application of a genetic risk score. In 2014, our group published a genetic risk score based on 13 eGFR- and CKD-related loci in 4,842 individuals of a founder population $(15.1 \%$ of whom had a diagnosis of CKD). The genetic risk score was higher in patients with CKD and in patients with faster eGFR decline [78]. This score was later revised by other groups following the discovery of new loci associated with either eGFR or CKD and tested in different populations [79].

\section{Recommendations and Conclusions}

$\mathrm{CKDu}$ is a serious global health problem. Recent years have seen increased awareness and worldwide collaboration which are pivotal in the attempt to control the epidemic. The existing evidence is diverse and complex, with several risk factors being reported in different settings, and currently there is no universally accepted pathogenetic hypothesis which could be extended to different endemic CKDu areas. The differences in the incidence of CKD development among patients exposed to similar environmental conditions suggest that individual risk fac-
Table 1. Future directions for $\mathrm{CKDu}$ screening and research

$\begin{array}{ll}\text { Modify screening } & \text { Implement occupational screening in at-risk } \\ \text { recommendations } & \text { populations } \\ & \text { Promote utilization of novel biomarkers of } \\ & \text { early kidney damage } \\ & \text { Standardize eGFR formulas for specific } \\ & \text { populations }\end{array}$

Define research agenda

Increase focus on the role of novel potential causal factors and cofactors, that is, heavy metals and metal chelators, local plants, and soil composition

Identify potential predisposing genetic factors

\begin{tabular}{|c|c|}
\hline $\begin{array}{l}\text { Expand the } \\
\text { research team }\end{array}$ & $\begin{array}{l}\text { Geologist } \\
\text { Toxicologist } \\
\text { Environmental chemist }\end{array}$ \\
\hline $\begin{array}{l}\text { Organize } \\
\text { involvement and } \\
\text { fund raising }\end{array}$ & $\begin{array}{l}\text { Local healthcare providers: hospitals and } \\
\text { rural doctors } \\
\text { Local government institutions } \\
\text { Medical associations: local nephrology } \\
\text { societies: ISN and ASN } \\
\text { Health and human services organizations: } \\
\text { CDC and NIH } \\
\text { Environmental agencies: EPA, independent } \\
\text { organizations, nongovernmental } \\
\text { organizations, and workers' foundations/ } \\
\text { associations: CAO, SALTRA program, and } \\
\text { La Isla foundation }\end{array}$ \\
\hline
\end{tabular}

$\mathrm{CKDu}$, chronic kidney disease of uncertain etiology; eGFR, estimated glomerular filtration rate; ISN, International Society of Nephrology; ASN, American Society of Nephrology; CDC, Center for Disease Control; NIH, National Institutes of Health; EPA, Environmental Protection Agency; CAO, Compliance Advisor/Ombudsman; SALTRA program, El Programa Salud Trabajo y Ambiente.

tors are unlikely to be responsible for $\mathrm{CKDu}$. It is more likely that an interaction between the proposed risk factors might contribute to the possible development of the disease and that CKDu risk might be proportional to the number and load of risk factors. Several authors suggest a central role for recurrent episodes of dehydration (due to heat stress and strenuous exercise). If this is accurate, global warming will inevitably lead to even greater disease burden in these and other vulnerable populations.

Renal replacement therapy is not widely available in most low- and middle-income countries. Therefore, identifying and implementing all known strategies to slow CKD progression is critical. On the basis of available data, we suggest adopting the following prevention measures in all at-risk populations: 
1. Receive adequate hydration: current US Army guidelines indicate $250 \mathrm{~mL} / \mathrm{h}$ of water during working activity with a temperature above $32^{\circ} \mathrm{C}[80]$.

2. Avoid the intake of high-fructose beverages and of informally produced spirits and limit the administration of known nephrotoxic drugs such as NSAIDs.

3. Extend community CKD screening in order to detect early loss of renal function, provide access to renal biopsy, and better characterize high-risk categories and areas.

4. Promote collaborative basic and clinical research in order to better understand the pathogenesis of $\mathrm{CKDu}$ and to identify protective strategies that might delay its development and progression. Research should also focus on potential genetic modifiers that may explain the variable susceptibility to $\mathrm{CKDu}$.

5. Implement social and political measures to guarantee access to safe drinking water and to limit exposure to toxic chemicals and metals.

6. Apply a collaborative approach to simultaneously examine clinical, epidemiological, and histological data from different global CKDu clusters to help better identify the pathogenesis. Future directions for screening and research are summarized in Table 1.

We suggest that CKDu might be caused by the interaction of a specific set of risk factors (which likely differ in geographically specific CKDu areas), which in the absence of protective factors might result in this unique disease. Further research is needed to identify additional novel risk factors in order to understand its pathogenesis and to develop effective therapies for this devastating disease.

\section{Acknowledgements}

The authors would like to express their gratitude to Mrs. Laura Lecca for her excellent secretarial assistance.

\section{Conflict of Interest Statement}

All authors declare no conflicts of interest.

\section{Funding Sources}

The manuscript was not funded.

\section{Author Contributions}

All authors conceived the manuscript and collected the literature; M.F., S.S., N.L., V.L., A.A., G.C., and D.P. drafted the manuscript; S.S., M.H.R., and A.P. provided a critical review of the manuscript; all authors edited and approved the final version of the manuscript.

\section{References}

1 Hill NR, Fatoba ST, Oke JL, Hirst JA, O'Callaghan CA, Lasserson DS, et al. Global prevalence of chronic kidney disease: a systematic review and meta-analysis. PLoS One. 2016 Jul 6;11(7):e0158765.

2 Ricardo AC, Madero M, Yang W, Anderson C, Menezes M, Fischer MJ, et al. Adherence to a healthy lifestyle and all-cause mortality in CKD. Clin J Am Soc Nephrol. 2013 Apr;8(4): 602-9.

3 Barsoum RS. Chronic kidney disease in the developing world. N Engl J Med. 2006 Mar 9; 354(10):997-9.

4 Nishijo M, Nakagawa H, Suwazono Y, Nogawa K, Kido T. Causes of death in patients with Itai-itai disease suffering from severe chronic cadmium poisoning: a nested case-control analysis of a follow-up study in Japan. BMJ Open. 2017;7(7):e015694.

5 Grollman AP, Shibutani S, Moriya M, Miller F, Wu L, Moll U, et al. Aristolochic acid and the etiology of endemic (Balkan) nephropathy. Proc Natl Acad Sci U S A. 2007;104(29): 12129-34.

6 Anand S, Caplin B, Gonzalez-Quiroz M, Schensul SL, Bhalla V, Parada X, et al. Epidemiology, molecular, and genetic methodologies to evaluate causes of CKDu around the world: report of the Working Group from the ISN International Consortium of Collaborators on CKDu. Kidney Int. 2019;96(6):1254-60.

7 Cuadra SN, Jakobsson K, Hogstedt C, Wesseling C. Chronic kidney disease: assessment of current knowledge and feasibility for regional research collaboration in Central America. Heredia, Costa Rica: SALTRA, IRET-UNA; 2006. p. 76 .

8 Gifford FJ, Gifford RM, Eddleston M, Dhaun N. Endemic nephropathy around the world. Kidney Int Rep. 2017 Mar;2(2):282-92.

9 Jayasumana C, Orantes C, Herrera R, Almaguer M, Lopez L, Silva LC, et al. Chronic interstitial nephritis in agricultural communities: a worldwide epidemic with social, occupational and environmental determinants. Nephrol Dial Transplant. 2017 Feb 1;32(2): 234-41.

10 Caplin B, Jakobsson K, Glaser J, Nitsch D, Jha $\mathrm{V}$, Singh A, et al. Rationale and core protocol for the Disadvantaged Populations eGFR Epidemiology Study (DEGREE). BMC Nephrol. 2017 Jan $3 ; 18(1): 1$.
11 Brooks DR. Epidemiology of CKD of unknown causes in Mesoamerica. In. Mesoamerican nephropathy: report from the first international research workshop on men. San Jose, CA: IRET \& SALTRA; 2012. p. 37-46. Abstract 1.

12 Correa-Rotter R, García-Trabanino R. Mesoamerican nephropathy. Semin Nephrol. 2019 May;39(3):263-71.

13 Torres C, Aragón A, González M, López I, Jakobsson K, Elinder CG, et al. Decreased kidney function of unknown cause in Nicaragua: a community-based survey. Am J Kidney Dis. 2010 Mar;55(3):485-96.

14 Cerdas M. Chronic kidney disease in Costa Rica. Kidney Int Suppl. 2005 Aug;(97):S31-3.

15 Correa-Rotter R, Wesseling C, Johnson RJ. CKD of unknown origin in Central America: the case for a Mesoamerican nephropathy. Am J Kidney Dis. 2014 Mar;63(3):506-20.

16 Ramirez-Rubio O, Brooks DR, Amador JJ, Kaufman JS, Weiner DE, Scammell MK, et al. Chronic kidney disease in Nicaragua: a qualitative analysis of semi-structured interviews with physicians and pharmacists. BMC Public Health. 2013 Apr;13(13):350. 
17 Wijkström J, González-Quiroz M, Hernandez M, Trujillo Z, Hultenby K, Ring A, et al. Renal morphology, clinical findings, and progression rate in Mesoamerican nephropathy. Am J Kidney Dis. 2017 May;69(5):626-36.

18 McClean MD, Amador JJ, Laws R, Kaufman JS, Weiner DE, Rodriguez JMS, et al. Biological sampling report: investigating biomarkers of kidney injury and chronic kidney disease among workers in Western Nicaragua. 2012.

19 Herrera R, Orantes CM, Almaguer M, Alfonso P, Bayarre HD, Leiva IM, et al. Clinical characteristics of chronic kidney disease of nontraditional causes in Salvadoran farming communities. MEDICC Rev. 2014 Apr;16(2): 39-48.

20 Tang S, Lai KN, Sacks SH. Role of complement in tubulointerstitial injury from proteinuria. Kidney Blood Press Res. 2002;25(2): 120-6.

21 Delgado Cortez O. Heat stress assessment among workers in a Nicaraguan sugarcane farm. Glob Health Action. 2009 Nov 11;2.

22 Chawla LS, Eggers PW, Star RA, Kimmel PL. Acute kidney injury and chronic kidney disease as interconnected syndromes. N Engl J Med. 2014 Jul 3;371(1):58-66.

23 Roncal Jimenez CA, Ishimoto T, Lanaspa MA, Rivard CJ, Nakagawa T, Ejaz AA, et al. Fructokinase activity mediates dehydrationinduced renal injury. Kidney Int. 2014 Aug; 86(2):294-302

24 Cirillo P, Gersch MS, Mu W, Scherer PM, Kim KM, Gesualdo L, et al. Ketohexokinasedependent metabolism of fructose induces proinflammatory mediators in proximal tubular cells. J Am Soc Nephrol. 2009 Mar; 20(3):545-53.

25 Ejaz AA, Beaver TM, Shimada M, Sood P, Lingegowda V, Schold JD, et al. Uric acid: a novel risk factor for acute kidney injury in high-risk cardiac surgery patients? Am J Nephrol. 2009;30(5):425-9.

26 Ejaz AA, Mu W, Kang DH, Roncal C, Sautin YY, Henderson G, et al. Could uric acid have a role in acute renal failure? Clin J Am Soc Nephrol. 2007 Jan;2(1):16-21.

27 Lang F, Guelinckx I, Lemetais G, Melander O. Two liters a day keep the doctor away? Considerations on the pathophysiology of suboptimal fluid intake in the common population. Kidney Blood Press Res. 2017;42(3):483-94.

28 Herath C, Jayasumana C, De Silva PMCS, De Silva PHC, Siribaddana S, De Broe ME. Kidney diseases in agricultural communities: a case against heat-stress nephropathy. Kidney Int Rep. 2018 Oct 24;3(2):271-80.

29 Cohen J. Mesoamerica's mystery killer. Science. 2014 Apr 11;344(6180):143-7.

30 Sanoff SL, Callejas L, Alonso CD, Hu Y, Colindres RE, Chin $\mathrm{H}$, et al. Positive association of renal insufficiency with agriculture employment and unregulated alcohol consumption in Nicaragua. Ren Fail. 2010;32(7):766-77.

31 Dalvi SR, Pillinger MH. Saturnine gout, redux: a review. Am J Med. 2013 May;126(5): $450-8$.
32 Raines N, González M, Wyatt C, Kurzrok M, Pool C, Lemma T, et al. Risk factors for reduced glomerular filtration rate in a Nicaraguan community affected by Mesoamerican nephropathy. MEDICC Rev. 2014 Apr;16(2): 16-22.

33 Wasinski B, Dutkiewicz J. Leptospirosis: current risk factors connected with human activity and the environment. Ann Agric Environ Med. 2013;20(2):239-44.

34 Bharti AR, Nally JE, Ricaldi JN, Matthias MA, Diaz MM, Lovett MA, et al. Leptospirosis: a zoonotic disease of global importance. Lancet Infect Dis. 2003 Dec;3(12):757-71.

35 Dika Ž, Juras J, Kos J, Edwards K, Fištrek M, Premužić V, et al. Prevalence, treatment and control of hypertension in a Croatian endemic nephropathy area. Kidney Blood Press Res. 2012;35(6):678-86.

36 Goonetilleke G. Agricultural accidents in north central Sri Lanka. Ceylon Med J. 1994 Mar;39(1):25-9.

37 Alwis K. Chronic kidney disease: when scientists disagree. Colombo, Sri Lanka: National Academy of Sciences of Sri Lanka; 2013.

38 Athuraliya NT, Abeysekera TD, Amerasinghe $\mathrm{PH}$, Kumarasiri R, Bandara P, Karunaratne U, et al. Uncertain etiologies of proteinuricchronic kidney disease in rural Sri Lanka. Kidney Int. 2011 Dec;80(11):1212-21

39 Jayatilake N, Mendis S, Maheepala P, Mehta FR; CKDu National Research Project Team. Chronic kidney disease of uncertain aetiology: prevalence and causative factors in a developing country. BMC Nephrol. 2013 Aug $27 ; 14: 180$

40 Ranasinghe AV, Kumara GWGP, Karunarathna RH, De Silva AP, Sachintani KGD, Gunawardena JMCN, et al. The incidence, prevalence and trends of chronic kidney disease and chronic kidney disease of uncertain aetiology $(\mathrm{CKDu})$ in the North Central Province of Sri Lanka: an analysis of 30,566 patients. BMC Nephrol. 2019 Aug 28;20(1):338.

41 Lanerolle RD, Nanayakkara S, Sheriffdeen AH, Sheriff R. Demographic characteristics of end stage renal disease in Sri Lanka. J Ceylon Coll Phy. 2000;33:2-8.

42 Wimalawansa SJ. Escalating chronic kidney diseases of multi-factorial origin in Sri Lanka: causes, solutions, and recommendations. Environ Health Prev Med. 2014 Nov;19(6):375-94.

43 Noble AD, Amerasinghe PH, Manthrithilake $\mathrm{H}$, Arasalingam S. Review of literature on chronic kidney disease of unknown etiology (CKDu) in Sri Lanka. Columbo, Sri Lanka: International Water Management Institute (IWMI); 2014.

44 Fernando BNTW, Alli-Shaik A, Hemage RKD, Badurdeen Z, Hettiarachchi TW, Abeysundara HTK, et al. Pilot study of renal urinary biomarkers for diagnosis of CKD of uncertain etiology. Kidney Int Rep. 2019 Jul 24; 4(10):1401-11.

45 Anand S, Montez-Rath ME, Adasooriya D, Ratnatunga N, Kambham N, Wazil A, et al. Prospective biopsy-based study of CKD of unknown etiology in Sri Lanka. Clin J Am Soc Nephrol. 2019 Feb 7;14(2):224-32.

46 Vervaet BA, Nast CC, Jayasumana C, Schreurs G, Roels F, Herath C, et al. Chronic interstitial nephritis in agricultural communities is a toxin-induced proximal tubular nephropathy. Kidney Int. 2020 Feb;97(2) $350-69$.

47 Siriwardhana EA, Perera PA, Sivakanesan R, Abeysekara T, Nugegoda DB, Jayaweera JA. Dehydration and malaria augment the risk of developing chronic kidney disease in Sri Lanka. Indian J Nephrol. 2015 May-Jun;25(3): $146-51$.

48 Jayasekara JM, Dissanayake DM, Adhikari SB, Bandara P. Geographical distribution of chronic kidney disease of unknown origin in North Central Region of Sri Lanka. Ceylon Med J. 2013 Mar;58(1):6-10.

49 Jayasumana C, Paranagama P, Agampodi S, Wijewardane C, Gunatilake S, Siribaddana S. Drinking well water and occupational exposure to herbicides is associated with chronic kidney disease, in Padavi-Sripura, Sri Lanka. Environ Health. 2015 Jan;14:6-.

50 Jayasumana C, Gunatilake S, Senanayake P. Glyphosate, hard water and nephrotoxic metals: are they the culprits behind the epidemic of chronic kidney disease of unknown etiology in Sri Lanka? Int J Environ Res Public Health. 2014;11(2):2125-47.

51 Liu X, Guan Y, Xu S, Li Q, Sun Y, Han R, et al. Early predictors of acute kidney injury: a narrative review. Kidney Blood Press Res. 2016; 41(5):680-700

52 Bandara JM, Senevirathna DM, Dasanayake DM, Herath V, Bandara JM, Abeysekara T, et al. Chronic renal failure among farm families in cascade irrigation systems in Sri Lanka associated with elevated dietary cadmium levels in rice and freshwater fish (tilapia). Environ Geochem Health. 2008 Oct;30(5):465-78.

53 Bandara JM, Wijewardena HV, Bandara YM, Jayasooriya RG, Rajapaksha H. Pollution of River Mahaweli and farmlands under irrigation by cadmium from agricultural inputs leading to a chronic renal failure epidemic among farmers in NCP, Sri Lanka. Environ Geochem Health. 2011 Oct;33(5):439-53.

54 Rango T, Jeuland M, Manthrithilake H, McCornick P. Nephrotoxic contaminants in drinking water and urine, and chronic kidney disease in rural Sri Lanka. Sci Total Environ. 2015 Jun;518-9:574-85.

55 Nanayakkara S, Senevirathna ST, Karunaratne U, Chandrajith R, Harada KH, Hitomi T, et al. Evidence of tubular damage in the very early stage of chronic kidney disease of uncertain etiology in the North Central Province of Sri Lanka: a cross-sectional study. Environ Health Prev Med. 2012 Mar;17(2):109-17.

56 Jayasumana MACS, Paranagama PA, Amarasinghe MD, Wijewardane KMRC, Dahanayake KS, Fonseka SI, et al. Possible link of chronic arsenic toxicity with chronic kidney disease of unknown etiology in Sri Lanka. J Nat Sci Res. 2013;3:64-73. 
57 Gamage CD, Sarathkumara YD. Chronic kidney disease of uncertain etiology in Sri Lanka: are leptospirosis and hantaviral infection likely causes? Med Hypotheses. 2016 Jun;91:169.

58 Mani MK. Chronic renal failure in India. Nephrol Dial Transplant. 1993 Aug;8(8):684-

59 Rajapurkar MM, John GT, Kirpalani AL, Abraham G, Agarwal SK, Almeida AF, et al. What do we know about chronic kidney disease in India: first report of the Indian CKD registry. BMC Nephrol. 2012 Mar 6;13:10.

60 Abraham G, Agarwal SK, Gowrishankar S, Vijayan M. Chronic kidney disease of unknown etiology: hotspots in India and other Asian countries. Nephrol. 2019 May;39(3): 272-7.

61 Ganguli A. Uddanam nephropathy/regional nephropathy in India: preliminary findings and a plea for further research. Am J Kidney Dis. 2016 Sep;68(3):344-8.

62 Glaser J, Lemery J, Rajagopalan B, Diaz HF, García-Trabanino R, Taduri G, et al. Climate change and the emergent epidemic of CKD from heat stress in rural communities: the case for heat stress nephropathy. Clin J Am Soc Nephrol. 2016 Aug 8;11(8):1472-83.

63 Ghosh R, Siddarth M, Singh N, Tyagi V, Kare $\mathrm{PK}$, Banerjee BD, et al. Organochlorine pesticide level in patients with chronic kidney disease of unknown etiology and its association with renal function. Environ Health Prev Med. 2017 May 26;22(1):49.

64 Aguilar DJ, Madero M. Other potential CKD hotspots in the world: the cases of Mexico and the United States. Semin Nephrol. 2019 May; 39(3):300-7.

65 Madero M, Aguilar D, Rana A, Escobar A, Villa A, Obrador G. Decreased kidney function among rural population in Tierra Blanca.
Mexico: a cross-sectional study. [Abstract] New Orleans, LA: Kidney Week 2017. J Am Soc Nephrol. 2017;28:529.

66 Mendoza-Patino N, De Leon-Rodriguez JA, Fernandez-Saavedra G. Toxicos renales en Tierra Blanca. Rev Fac Med UNAM. 2006;49: $34-7$

67 El Minshawy O. End-stage renal disease in the El-Minia Governorate, upper Egypt: an epidemiological study. Saudi J Kidney Dis Transpl. 2011 Sep;22(5):1048-54.

68 Kamel EG, El Minshawy O. Environmental factors incriminated in the development of end stage renal disease in El-Minia Governorate, Upper Egypt. Int J Nephrol Urol. 2010;2: 431-7.

69 Hassen W, Abid S, Achours A, Maaroufi K, Creppy EE, Bacha H. Ochratoxin A and human nephropathy in Tunisia: a ten years survey Annales de Toxicology. Analitique. 2003; 14(1).

70 Hmaissia Khlifa K, Ghali R, Mazigh C, Aouni Z, Machgoul S, Hedhili A. Ochratoxin A levels in human serum and foods from nephropathy patients in Tunisia: Where are you now? Exp Toxicol Pathol. 2012 Jul;64(5):509-12.

71 Nanayakkara S, Senevirathna ST, Parahitiyawa NB, Abeysekera T, Chandrajith R, Ratnatunga $\mathrm{N}$, et al. Whole-exome sequencing reveals genetic variants associated with chronic kidney disease characterized by tubulointerstitial damages in North Central Region, Sri Lanka. Environ Health Prev Med. 2015 Sep; 20(5):354-9.

72 Siddarth M, Datta SK, Ahmed RS, Banerjee BD, Kalra OP, Tripathi AK, et al. Association of CYP1A1 gene polymorphism with chronic kidney disease: a case control study. Environ Toxicol Pharmacol. 2013 Jul;36(1):164-70.

73 Siddarth M, Datta SK, Mustafa M, Ahmed RS, Banerjee BD, Kalra OP, et al. Increased level of organochlorine pesticides in chronic kidney disease patients of unknown etiology: role of GSTM1/GSTT1 polymorphism. Chemosphere. 2014 Feb;96:174-9.

74 Divers J, Freedman BI. Genetics in kidney disease in 2013: susceptibility genes for renal and urological disorders. Nat Rev Nephrol. 2014 Feb;10(2):69-70.

75 Lhotta K, Piret SE, Kramar R, Thakker RV, Sunder-Plassmann G, Kotanko P. Epidemiology of uromodulin-associated kidney disease results from a nation-wide survey. Nephron Extra. 2012 Jan;2(1):147-58.

76 Gast C, Marinaki A, Arenas-Hernandez M, Campbell S, Seaby EG, Pengelly RJ, et al. Autosomal dominant tubulointerstitial kidney disease-UMOD is the most frequent non polycystic genetic kidney disease. BMC Nephrol. 2018 Oct 30;19(1):301.

77 Groopman EE, Marasa M, Cameron-Christie S, Petrovski S, Aggarwal VS, Milo-Rasouly $\mathrm{H}$, et al. Diagnostic utility of exome sequencing for kidney disease. N Engl J Med. 2019 Jan 10; 380(2):142-51.

78 Pani A, Bragg-Gresham J, Masala M, Piras D, Atzeni A, Pilia MG, et al. Prevalence of CKD and its relationship to eGFR-related genetic loci and clinical risk factors in the SardiNIA study cohort. J Am Soc Nephrol. 2014 Jul; 25(7):1533-44.

79 Schulz CA, Engström G, Christensson A, Nilsson PM, Melander O, Orho-Melander M. Genetic predisposition for renal dysfunction and incidence of CKD in the Malmö Diet and Cancer Study. Kidney Int Rep. 2019 May 16; 4(8):1143-51.

80 Kolka MA, Latzka WA, Montain SJ, Sawka NM. Current U.S. military fluid replacement guidelines. In. Maintaining hydration: issues, guidelines, and delivery. Boston, MA: AGARD \& RTO; 2004. 